\title{
Hydrogen Sulfide Gas Sensor Based on Conducting Polyimide/Gold Nanoparticles
}

\author{
Lee Marvin G. Padua ${ }^{1}$, Jui-Ming Yeh², Karen S. Santiago ${ }^{1,3}$ \\ ${ }^{1}$ Department of Chemistry, College of Science, University of Santo Tomas, España Blvd., Manila \\ 1015, Philippines, \\ ${ }^{2}$ Department of Chemistry, Center for Nanotechnology, Chung Yuan Christian University, Taiwan \\ ${ }^{3}$ Research Center for the Natural and Applied Sciences, University of Santo Tomas, España Blvd. \\ Manila 1015, Philippines \\ Corresponding author's e-mail address kssantiago@ust.edu.ph
}

\begin{abstract}
:
This work presents the development of $\mathrm{H}_{2} \mathrm{~S}$ gas sensor based on conducting polyimide/gold nanoparticles (CPI/AuNPs). The sensing membrane was prepared via a facile two-step process of polymerization and imidization to obtain CPI, followed by incorporation of AuNPs into the polymer matrix through reduction of $\mathrm{HAuCl}_{4}$. The success of synthesis was confirmed via Fourier transform infrared spectroscopy (FTIR) and scanning electron microscopy-energy dispersive X-rays (SEM-EDX). The FTIR spectra confirmed the presence of functional groups that constitute the polymer, while its morphological structure and EDX spectra revealed small white globules on the surface of the polymer, and Au peaks, respectively, that could be attributed to the incorporation of AuNPs. The gas sensor was constructed by drop casting CPI/AuNPs onto two circular gold substrates separated by a gap distance of $500 \mu \mathrm{m}$. The fabricated CPI/AuNPs-based gas sensor showed a sensitivity of $-0.29 \%$ $\mathrm{ppm}^{-1} \mathrm{H}_{2} \mathrm{~S}$ from 50 to $300 \mathrm{ppm} \mathrm{H}_{2} \mathrm{~S}$ at a linearity of $0.9731(\mathrm{n}=3)$. The sensor provided a stable response reading at an average response time of 51 seconds, which can be easily recovered after an average of 103 seconds. The response was highly repeatable and reproducible with an RSD of $6.05 \%$ and $5.96 \%$, respectively. The sensor shows high reversibility with an RSD of $8.42 \%$.
\end{abstract}

Key words: gas sensor, conducting polymer, gold nanoparticles, hydrogen sulfide gas

\section{Introduction}

Hydrogen sulfide $\left(\mathrm{H}_{2} \mathrm{~S}\right)$ is a dangerous and corrosive gas commonly produced in sewage, and regarded responsible for sewage pipe corrosion. It has been reported that when $\mathrm{H}_{2} \mathrm{~S}$ gas reacts with the moisture on the walls of the pipe, it leads to the formation of caustic sulfuric acid, which corrodes the pipelines and other surfaces of the sewage systems [1, 2]. This condition consequently increases $\mathrm{H}_{2} \mathrm{~S}$ level released into the air that may cause adverse health effects.

Gas chromatography-flame photometric detector (GC/FPD), is recommended for the analysis of $\mathrm{H}_{2} \mathrm{~S}$ gas in the environment [3]. However, this technique is laborious, timeconsuming, and expensive. To address these concerns, this study seeks for a possible alternative, and focuses on the fabrication of a reasonably priced and simple to operate CPI/AuNPs-based gas sensor for monitoring $\mathrm{H}_{2} \mathrm{~S}$.

\section{Methodology}

Preparation and characterization of CPI/AuNPs. Synthesized aniline trimer (AniT) was dissolved in dimethylacetamide (DMAc, Sigma - Aldrich), and the resulting solution was thoroughly mixed by sonication. The $4,4^{\prime}-(4,4$ 'isopropylinedene diphenoxy)bis(phthalic anhydride) (BSAA, 97\%, Aldrich) was added to AniT/DMAc then stirred for $24 \mathrm{~h}$ at RT. After stirring, acetic anhydride and pyridine were added then stirred. The mixture was refluxed for $3 \mathrm{~h}$ in nitrogen environment at $150^{\circ} \mathrm{C}$. After $3 \mathrm{~h}$, the solution was allowed to cool for 10 to 20 min before adding methanol, and stirred for another $10 \mathrm{~min}$. The mixture was subjected to 
vacuum filtration then the residue was dried using vacuum dry oven (DOV30, Deng Yng). $\mathrm{CPI}$ was mixed with gold(III)chloride trihydrate $\left(\mathrm{HAuCl}_{4} \cdot 3 \mathrm{H}_{2} \mathrm{O}, 99.99 \%\right.$, Alfa Aesar) and DMAc, and the resulting mixture was stirred for $6 \mathrm{~h}$ at RT. Vacuum filtration and vacuum drying were carried out to obtain CPI/AuNPs. Synthesized materials were characterized using spectral and surface techniques.

Evaluation of CPI/AuNPs-based gas sensor performance. The gas sensor was constructed by drop casting a mixture of CPI/AuNPs onto two gold substrates separated by a gap distance of $500 \mu \mathrm{m}$. The sensor performance was evaluated towards varying concentrations of $\mathrm{H}_{2} \mathrm{~S}$.

\section{Results and discussion}

The CPI was synthesized via a two-step process of polymerization and imidization. The FTIR spectra revealed the characteristic peaks of the synthesized polymer. On the other hand, morphological investigations confirmed AuNPs incorporation into the polymer matrix.

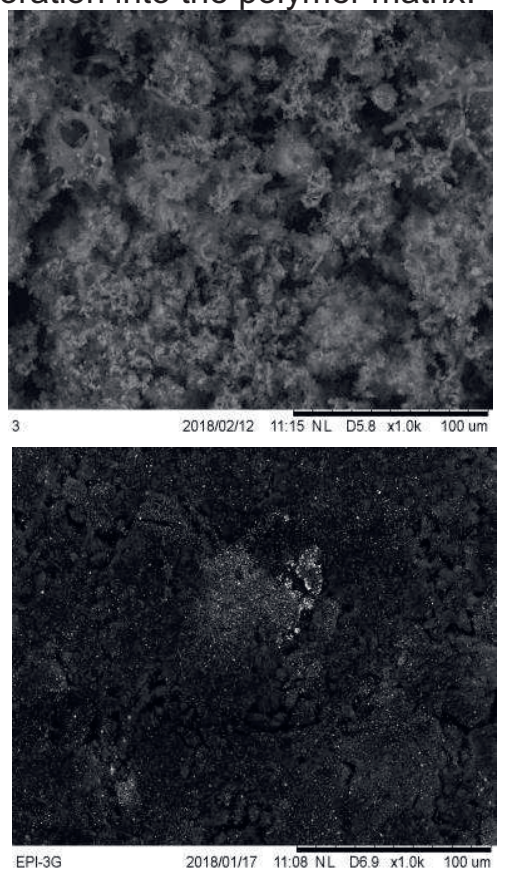

Fig. 1. SEM micrographs of (a) $\mathrm{CPI}$ and (b) CPI/AuNPs at 1000x magnification.

Figure 2 shows the calibration curve based on the performance of CPI/AuNPs towards increasing concentration of hydrogen sulfide gas. The sensor showed a sensitivity of $-0.29 \%$ $\mathrm{ppm}^{-1} \mathrm{H}_{2} \mathrm{~S}$, and a linearity of 0.9731 from 50 to $300 \mathrm{ppm} \mathrm{H}_{2} \mathrm{~S}(\mathrm{n}=3)$. The sensor exhibited an average response time of $51 \mathrm{~s}$ that can easily be recovered at an average of $103 \mathrm{~s}$. Based on data gathered, the sensor showed high reversibility with an RSD of $8.42 \%$. Furthermore, the gas sensor response was highly repeatable and reproducible with an RSD of $6.05 \%$ and $5.96 \%$, respectively.

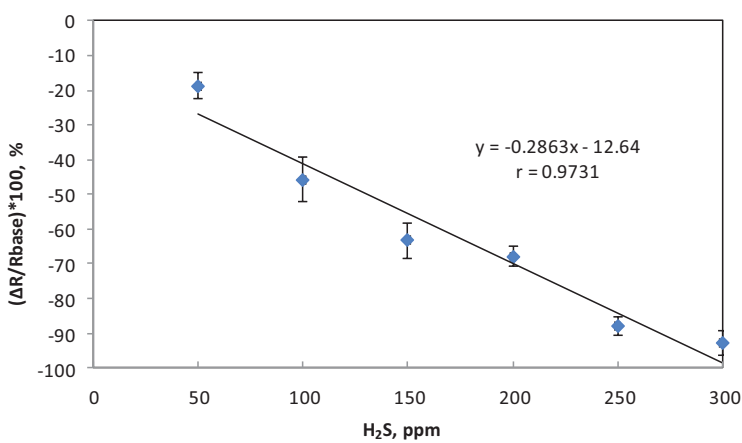

Fig. 2. Response of CPI/AuNPs-based gas sensor as a function of $\mathrm{H}_{2} \mathrm{~S}$ concentration ( $\left.n=3\right)$.

\section{Conclusion}

A hydrogen sulfide gas sensor based on conducting/gold nanoparticles has been fabricated. FTIR spectra confirmed successful synthesis of the $\mathrm{CPI}$, and SEM-EDX results confirmed the presence of AuNPs. Data gathered are promising in terms of monitoring trace level concentrations of $\mathrm{H}_{2} \mathrm{~S}$ using $\mathrm{CPI} / A u N P s$ as sensing membrane.

\section{References}

[1] K. Park, H. Lee, S. Phelan, S. Liyanaarachchi, N. Marleni, D. Navaratna, V. Jegatheesan, L. Shu, Mitigation strategies of hydrogen sulphide emission in sewer networks: A review, International Biodeterioration \& Biodegradation 95 (2014) 251-261.

[2] E. Stanaszek-Tomal, and M. Fiertak, Biological Corrosion in The Sewage System and The Sewage Treatment Plant, Procedia Engineering 161 (2016) $116-120$.

[3] U.S. EPA, Method 15: Determination of Hydrogen Sulfide, Carbonyl Sulfide and Carbon Disulfide Emissions from Stationary Sources, Air Emissions Measurement Center, Washington DC, 2017. 